\title{
Perceived Perfectionism from God Scale: Development and Initial Evidence
}

\author{
Kawika Allen \\ Brigham Young University, gekawika_allen@byu.edu \\ Kenneth T. Wang \\ Fuller Theological Seminary, ktwang@fuller.edu \\ Hannah I. Stokes \\ Brigham Young University, stokes.hannah.lashell@gmail.com \\ Han Na Suh \\ University of Missouri, hsm7b@mail.missouri.edu
}

Follow this and additional works at: https://scholarsarchive.byu.edu/facpub

Part of the Mental and Social Health Commons

\section{Original Publication Citation}

Wang, K. T., Allen, G. E. K., *Stokes, H., \& *Suh, H. N. (2018). Perceived perfectionism from God Scale: Development and initial evidence. Journal of Religion and Health, 57(6), 2207-2223.

\section{BYU ScholarsArchive Citation}

Allen, Kawika; Wang, Kenneth T.; Stokes, Hannah I.; and Suh, Han Na, "Perceived Perfectionism from God Scale: Development and Initial Evidence" (2017). Faculty Publications. 3178.

https://scholarsarchive.byu.edu/facpub/3178

This Peer-Reviewed Article is brought to you for free and open access by BYU ScholarsArchive. It has been accepted for inclusion in Faculty Publications by an authorized administrator of BYU ScholarsArchive. For more information, please contact ellen_amatangelo@byu.edu. 


\section{Perceived Perfectionism from God Scale: Development and Initial Evidence}

\section{Kenneth T. Wang, G. E. Kawika Allen, Hannah I. Stokes \& Han Na Suh}

Journal of Religion and Health

ISSN 0022-4197

J Relig Health

DOI 10.1007/s10943-017-0405-1

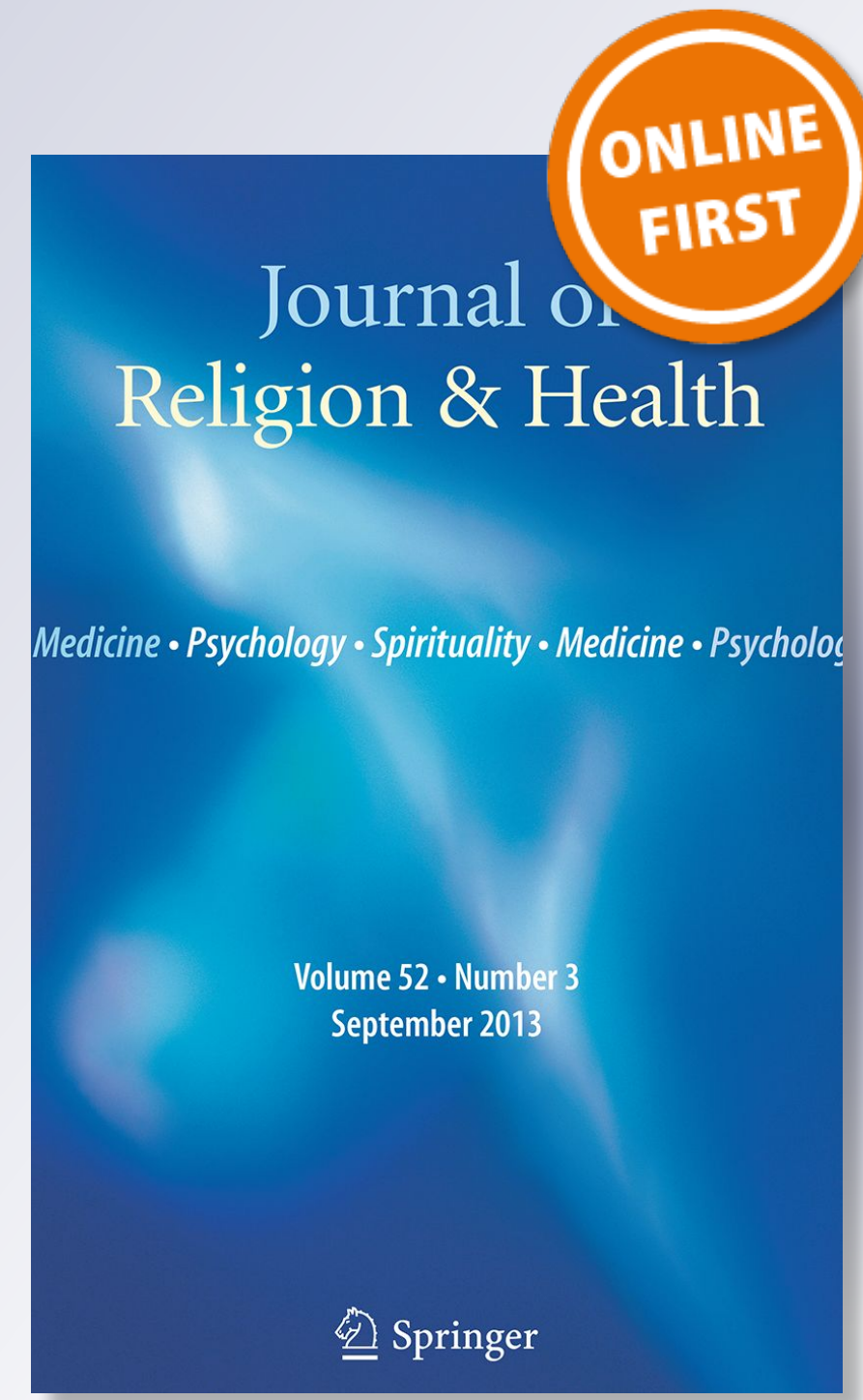

算 Springer 
Your article is protected by copyright and all rights are held exclusively by Springer Science +Business Media New York. This e-offprint is for personal use only and shall not be selfarchived in electronic repositories. If you wish to self-archive your article, please use the accepted manuscript version for posting on your own website. You may further deposit the accepted manuscript version in any repository, provided it is only made publicly available 12 months after official publication or later and provided acknowledgement is given to the original source of publication and a link is inserted to the published article on Springer's website. The link must be accompanied by the following text: "The final publication is available at link.springer.com". 


\title{
Perceived Perfectionism from God Scale: Development and Initial Evidence
}

\author{
Kenneth T. Wang ${ }^{1}$ G. E. Kawika Allen ${ }^{2}$ Hannah I. Stokes ${ }^{2}$ • \\ Han $\mathrm{Na} \mathrm{Suh}^{3}$
}

(C) Springer Science+Business Media New York 2017

\begin{abstract}
In this study, the Perceived Perfectionism from God Scale (PPGS) was developed with Latter-day Saints (Mormons) across two samples. Sample $1(N=421)$ was used for EFA to select items for the Perceived Standards from God (5 items) and the Perceived Discrepancy from God (5 items) subscales. Sample $2(N=420)$ was used for CFA and cross-validated the 2-factor oblique model as well as a bifactor model. Perceived Standards from God scores had Cronbach alphas ranging from .73 to .78, and Perceived Discrepancy from God scores had Cronbach alphas ranging from .82 to .84 . Standards from God scores were positively correlated with positive affect, whereas Discrepancy from God scores was positively correlated with negative affect, shame and guilt. Moreover, these two PPGS subscale scores added significant incremental variances in predicting associated variables over and above corresponding personal perfectionism scores.
\end{abstract}

Keywords Perfectionism - Scale development · Latter-day Saints · Religiosity · Psychometric

Kenneth T. Wang

ktwang@fuller.edu

G. E. Kawika Allen

gekawika_allen@byu.edu

Hannah I. Stokes

stokes.hannah.lashell@gmail.com

Han Na Suh

hsm7b@mail.missouri.edu

1 Department of Clinical Psychology, Fuller Theological Seminary, Pasadena, CA, USA

2 Department of Counseling Psychology and Special Education, Brigham Young University, Provo, UT, USA

3 Department of Education, School and Counseling Psychology, University of Missouri, Columbia, MO, USA 


\section{Introduction}

Perfectionism has been linked to religious individuals by several scholars over the past few decades (e.g., Allen and Wang 2014; Crosby et al. 2011; Ellis 1986; Heise and Steitz 1991). For example, Ellis suggested that those who rigidly adhere to religious teachings with absolutes and perfection are often more distressed compared to those with relatively flexible religious beliefs. Crosby et al. emphasized high standards as the shared commonality between perfectionism and religiosity. The perfectionism and religion connection can also be traced back to biblical teachings that have had an influence on the development of morality among Christians in the Western world (Heise and Steitz 1991).

It is argued that biblical teachings have contributed to the perfectionistic striving in the Western society and especially among Christians (Heise and Steitz 1991). For example, the Bible verse, "You therefore must be perfect, as your heavenly Father is perfect." (Matthew $5: 48)$ literally suggests a striving for perfection, although the interpretation of what being perfect means may differ across denominations, churches, and individuals. Historically, "Christian perfection" is a doctrine that originated in the 18th century England and was radicalized in the USA during the early 19th century (Warner 2009). This Christian perfection movement established moral codes, such as the prohibition of using innutritious stimulants (Warner 2009), to which has been closely adhered by Latter-day Saints with the highest rates of abstention among American churches (Michalak et al. 2007). The association between perfectionism and religiosity among religious communities, such as Latterday Saints, in the USA is clearly worth further researching.

A main doctrine of the Latter-day Saints church is "to be made perfect" (Mormon scripture), which emphasizes high moral and values-based standard of living. Despite the strong link between perfectionism and religiosity suggested by scholars, there have been relatively few empirical studies that have examined religiosity within the perfectionism literature. A few empirical studies on perfectionism and religiosity were located. Among the studies of this topic area, a few research questions were examined. Several studies focused on the relationship between perfectionism and religious motivation or commitment (Allen and Wang 2014; Crosby et al. 2011; Rasmussen et al. 2013). Another study examined the association between family environment and religious perfectionism, in which family rigidity was found to be the strongest family environment factor predicting dysfunctional religious perfectionism (Craddock et al. 2010). In addition, perfectionism was found to be associated with scrupulosity (i.e., an overly obsessive fear of sinning and disappointing God) as well as guilt and shame among Latter-day Saints (Allen and Wang 2014; Allen et al. 2015). These studies not only provide empirical support for the link between perfectionism and religiosity, but also highlight the importance of distinguishing between adaptive and maladaptive perfectionism.

Through sampling of dictionaries, Slaney et al. (2001) identified two major definitions of perfectionism- "extreme or excessive striving for perfection" and "a disposition to regard anything short of perfection as unacceptable" (p. 131). In turn, Slaney and colleagues developed the Almost Perfect Scale-Revised (APS-R) with subscales of Standards and Discrepancy to reflect these two key definitions, respectively. Perfectionism has also been established as having both adaptive and maladaptive aspects (Stoeber and Otto 2006). The adaptive aspect of perfectionism focuses on striving and setting high standards, whereas the maladaptive aspect of perfectionism is characterized by an evaluative concern that focuses on the discrepancy between one's perceived ideal and performance. These two different aspects of perfectionism have been found to relate differently with religious 
variables. For example, adaptive perfectionism was found to positively correlate with intrinsic religious orientation; in contrast, maladaptive perfectionism was found to positively correlate with extrinsic religious orientation (Crosby et al. 2011). Moreover, having high perfectionistic standards was positively correlated with religious commitment, whereas having high perfectionistic discrepancies was negatively correlated with religious commitment (Allen and Wang 2014). These findings correspond with the literature supporting the multidimensionality of perfectionism (Stoeber and Otto 2006).

There have been an increasing number of studies examining perfectionism as a multidimensional construct and how the various dimensions differentially associated with mental health indicators over the past decade. In particular, the tendency to strive for perfection has been theoretically and empirically suggested to be healthy and associated with higher self-esteem and better performance (Grzegorek et al. 2004; Rice and Slaney 2002). In contrast, the overly focus on imperfection (i.e., discrepancy between standards and perceived performance) has been the defining maladaptive aspect of perfectionism, which has been strongly associated with mental health concerns such as depression, anxiety, eating disorder and interpersonal problems. (Patterson et al. 2012; Slaney et al. 2006; Wang et al. 2007). Moreover, the multidimensionality of perfectionism has not only been distinguished by the adaptive and maladaptive aspects, but also by the orientation and directionality of the perfectionistic expectations and concerns. Most notable is Hewitt and Flett's (1991) Multidimensional Perfectionism Scale that was established based on three dimensions: self-oriented perfectionism (perfectionistic expectations imposed on oneself), other-oriented perfectionism (perfectionistic expectations imposed on others) and socially prescribed perfectionism (perceive that significant others impose perfectionistic expectations on oneself), which were differentiated by orientation-directionality. Therefore, there seems to be at least two higher-order dimensions of perfectionism: one distinguishing the adaptive-maladaptive nature, whereas the other distinguishing the orientation-directionality of perfectionism. We suggest that these two higher-order dimensions are independent of each other and should not be confused by lumping the two together. For example, we believe that it is inappropriate to simply categorize perfectionism originating from external sources as all being maladaptive. Measures assessing alternate sources of perfectionistic standards and concerns (e.g., dyadic and family perfectionism scales) can be viewed simply as a subset of Hewitt and Flett's Socially Prescribed Perfectionism. However, we argue for distinctions across adaptive/maladaptive nature as well as source/orientation of perfectionism. Examples of measures that have utilized this distinction include the Family Almost Perfect Scale (Wang 2010) that specifically focuses on perceived perfectionism (both adaptive and maladaptive) from one's family (external source). Another example is the Dyadic Almost Perfect Scale (Shea et al. 2006), which measures both adaptive and maladaptive perfectionism that one has for an intimate partner (toward another person). We further propose the value of examining perceived perfectionistic standards and concerns that religious individuals might have from their God (or Higher Power), which is a different type of external source.

A main goal of this study is to develop a scale that measures perceived perfectionism from God, which includes both adaptive and maladaptive components. So far only one existing scale measures perfectionism related to religiosity. The Religious Dysfunctional Perfectionism Scale (RDPS; Craddock et al. 2010) was modified based on items from the Frost Multidimensional Perfectionism Scale (Frost et al. 1990) that measured general dysfunctional perfectionism. The RDPS focuses on unhelpful and negative feelings about the quality of involvement in religious activity. Sample RDPS items include: "I feel that I set higher goals in my religious activities than most people." and "I hate being less than 
the best in my religious activities." Although the RDPS offers the ability to assess one's perfectionism in the religious domain, it does not distinguish the sources of perfectionistic expectations nor does it differentiate adaptive and maladaptive components. Thus, our proposed Perceived Perfectionism from God Scale (PPGS) not only focuses on the perceived or projected level of perfectionism from God, but also includes both the adaptive striving as well as the maladaptive concerns. PPGS was modified from the Almost Perfect Scale-Revised and focuses on two key dimensions-Standards and Discrepancy, which have been the defining adaptive and maladaptive aspects of perfectionism, respectively (Slaney et al. 2001).

In this study, we utilized two samples of Latter-day Saints: one to select scale items through exploratory factor analysis and the other to cross-validate the factor structure through confirmatory factor analysis. We also examined the construct validity of the PPGS through its associations with personal perfectionism, religious variables (i.e., religious commitment, legalistic beliefs, scrupulosity), and mental health indicators (i.e., subjective well-being, guilt and shame). Subjective well-being is defined as the relative presence of positive affect, the absence of negative affect, and positive cognitive appraisal of life satisfaction (Pavot and Diener 1993). We examined convergent validity through exploring whether PPGS significantly relates to a measure of personal perfectionism (i.e., Short Almost Perfect Scale). In addition, considering that PPGS measures perfectionistic beliefs about God, we expected there to be significant relationships with religious constructs. More specifically, the adaptive aspect of PPGS is expected to positively associate with positive religiosity (e.g., religious commitment) and the maladaptive aspect of perfectionism with negative religiosity (e.g., scrupulosity). These hypotheses are based on previous studies (Ashby and Huffman 1999; Crosby et al. 2011) that found similar distinctions between adaptive and maladaptive perfectionism. Furthermore, research on perfectionism share similar results of how the two different aspects of perfectionism differentially relate to psychological outcomes (e.g., Bieling et al. 2004; Crosby et al. 2011). Thus, we expected that Standards, the adaptive aspect of PPGS, would significantly relate to subjective wellbeing, whereas Discrepancy, the maladaptive aspect of PPGS, would significantly relate to guilt and shame. If confirmed, these results would also serve as evidences for construct validity. In addition, we examine the incremental validity of the PPGS Standards and Discrepancy scores in predicting religious commitment and scrupulosity above and beyond their corresponding personal perfectionism dimensions.

\section{Method}

\section{Participants}

Participants across two samples were all Latter-day Saints (Mormons). Sample 1 consisted of 421 (208 men, 211 women, 2 did not report) participants. The majority of participants were White $(87 \%)$ and from suburban settings $(72 \%)$. The mean age of participants was 23.05 (SD = 5.06). Sample 2 consisted of 420 (212 men, 208 women) participants. The majority of participants were White (89\%) and from suburban settings (71\%). Participants' mean age was $23.56(\mathrm{SD}=5.21)$.

Data were all collected through the Qualtrics online survey program. Participants were invited to participate through recruiting college students at a large university in the Southwestern region, and through social media (e.g., Facebook). Participants recruited 
through the university were rewarded extra course credit, and those recruited through social media were compensated with a $\$ 10$ gift card.

Participants in each sample were almost equally split between the two recruitment methods (Sample 1: university: $n=214$, social media: $n=207$; Sample 2: university: $n=212$, social media: $n=208$ ). A series of t tests were conducted between those recruited from the university and through social media. The two sources of participants did not differ $(p>.05)$ on most of the key variables related to their religiosity (i.e., Religious Commitment, Legalism) and psychological well-being (e.g., Shame \& Guilt, Negative Affect, Positive Affect, Satisfaction with Life). However, participants recruited from the university had higher scrupulosity scores than those recruited from social media $[t(839)=4.78, p<.001]$. Participants recruited from the university $(M=22.11$, $\mathrm{SD}=3.43)$ were younger $[t(828)=6.99, p<.001]$ than those recruited from social media $(M=24.53, \mathrm{SD}=6.21)$. There was also a higher representation of men $\left[\chi^{2}(1)=59.28, p<.001\right]$ among those recruited from the university $(63 \%)$ than those from social media (37\%). Despite some differences in age and gender, the LDS participants recruited from the two methods were comparable on most of the religious and psychological indicators of religiosity and psychological well-being. Thus, we aggregated these two different sources of LDS participants in our analyses.

\section{PPGS Item Development}

The PPGS items were developed by altering the Standards and Discrepancy items from the Almost Perfect Scale-Revised (APS-R; Slaney et al. 2001) to reflect the level of perceived perfectionistic expectations and concerns from God. For example, the APS-R Standards item "I set very high standards for myself" was modified into "God sets very high standards for me" for the PPGS. The APS-R Discrepancy item "I am hardly ever satisfied with my performance" was modified into "God is hardly ever satisfied with my performance."

\section{Other Measures}

\section{Short Almost Perfect Scale (SAPS; Rice et al. 2014)}

The SAPS was used to measure personal perfectionism. It consists of two subscalesStandards (4 items) and Discrepancy (4 items). The Standards subscale measures the level of perfectionistic striving by setting high personal expectations. A sample item is "I set very high standards for myself." The Discrepancy subscale measures the level of perfectionistic concerns through the tendency to perceive a gap between one's standards and performance. A sample item is "I am hardly ever satisfied with my performance." Participants rated each item on a seven-point Likert scale: 1 (strongly disagree) to 7 strongly agree). The Cronbach alphas ranged from .85 to .87 for Standards and .84 to .87 for Discrepancy (Rice et al., 2014). In the current study, the Cronbach alphas of Standards and Discrepancy scores were .87 and .87 , respectively.

\section{Religious Commitment Inventory-10 (RCI-10; Worthington et al. 2003)}

The RCI-10 was used to measure religious commitment. It consists of 10 items and two factors: intrapersonal (cognitive focus) and interpersonal (behavioral focus). Sample items 
include, "It is important to me to spend periods of time in private religious thought and reflection" (intrapersonal) and "I enjoy working in the activities of my religious organization" (interpersonal). Participants rated each item on a five-point Likert scale: 1 (not at all true of me) to 5 (totally true of me). Intrapersonal and Interpersonal Religious Commitment were highly correlated, and test-retest reliability over a 5-month period was .91 (Worthington et al. 2003). The Cronbach alpha for the RCI-10 composite score was .94 in a sample of LDS people (Allen and Heppner 2011). In the current study, the Cronbach alpha of the composite RCI-10 scores was .91.

\section{Graceful Avoidance of Personal Legalism (GAPL; Watson et al. 2011)}

The GAPL subscale of the Richmont Grace Scale (RGS; Watson et al. 2011) was used to measure legalism in this study. The GAPL is designed to measure contrasting assumptions common to Christians: God's favor that is earned vs. God's grace freely given. The GAPL is a four-item self-report measure based on a 5-point Likert scale ranging from 1 (strongly disagree) to 5 (strongly agree). Higher scores indicate a stronger belief that one must earn God's favor through works (legalism). Sample items include "I must work hard to experience God's grace and forgiveness" and "The harder I work, the more I earn God's favor." The Cronbach alpha was .61 in the original study (Watson et al. 2011). In the current study, the Cronbach alpha was .63. According to DeVellis (2012), an internal consistency between .60 to .65 is viewed as undesirable, but not unacceptable.

\section{Penn Inventory of Scrupulosity (PIOS; Abramowitz et al. 2002)}

The PIOS was used to measure scrupulosity. It is a 19-item self-report measure rated on a Likert scale ranging from 0 (never) to 4 (constantly). The PIOS includes two subscales: Fear of Sin (12 items) and Fear of God (7 items). Sample items include "I feel urges to confess sins over and over again" (Fear of Sin) and "I worry I will never have a good relationship with God" (Fear of God). The Cronbach alpha for the composite score was 93 in Abramowitz et al.'s original study. In the current study, the Cronbach alpha for the composite PIOS scores was .93.

\section{Positive and Negative Affect Schedule (PANAS; Watson et al. 1988)}

The PANAS was used to assess positive affect (PA; e.g., enthusiastic, interested, attentive) and negative affect (NA; e.g., scared, distressed, irritable) over the past week. Each item was rated on a 5-point Likert scale ranging from 1 (very slight or not at all) to 5 (extremely). Cronbach alphas were .89 for PA scores and .85 for NA scores in a large nonclinical adult sample (Crawford and Henry 2004). In the current study, Cronbach alpha was .89 for PA scores, and .84 for NA scores.

\section{Satisfaction with Life Scale (SWLS; Pavot and Diener 1993)}

SWLS was used to measure life satisfaction. It consists of 5 items that assesses the general level of life satisfaction. Each item is rated on a 7-point Likert scale ranging from 1 (strongly disagree) to 7 (strongly agree). A sample item is "I am satisfied with my life." Cronbach alphas ranged from .79 to .89 in studies of various samples (Pavot and Diener 1993). In this current study, the Cronbach alpha for SWLS scores was .86. 
State Shame and Guilt Scale (SSGS; Marschall et al. 1994)

The SSGS was used to measure shame and guilt. The composite score of two SSGS subscales-Shame (5 items) and Guilt (5 items) were used in this study. Items were measured with a Likert scale ranging from 1 (not feeling this way at all) to 5 (feeling this way very strongly). Sample items include "I feel humiliated, disgraced" (Shame) and "I feel remorse, regret" (Guilt). Cronbach alphas were .87 for Shame and .87 for Guilt (Stoeber et al. 2007). In the current study, the Cronbach alpha for the composite Shame and Guilt scores was .93.

\section{Marlowe and Crowne Social Desirability Scale-Short A (MCSDS-Short A; Crowne and Marlowe 1960)}

The MCSDS assesses the tendency for participants to respond in socially approved ways. The scale originally contained 33 true-false items referring to socially approved but uncommon behaviors (e.g., I have never intensely disliked anyone) and socially disapproved but common behaviors (e.g., I like to gossip at times). Reynolds (1982) developed three MCSDS short forms A, B, and C. Form A was proved to be a significant improvement in fit over the full scale and concluded as one of the best fitting short forms (Loo and Thorpe 2000). In Loo and Thorpe's (2000) study, the correlation between form A and the full MCSDS was high $(r=.87)$. In the current study, the Cronbach alpha for the 11 item A form yielded a Cronbach alpha of .64 .

\section{Results}

The first sample $(N=421)$ was used for exploratory factor analysis (EFA) to select the scale items. The second sample $(N=420)$ was used for confirmatory factor analyses (CFA) to cross-validate the factor structure results from the EFA as well as examine the correlations and incremental validity. Cases $(n=3)$ with missing data over $5 \%$ were removed; and for the remaining cases, missing data were replaced by series means. Univariate outliers were identified and examined; through a visual inspection of response patterns, the cases with outlying scores did not appear to be invalid (e.g., lack of variance, strange patterns). Thus, they were kept in the study for subsequent analyses.

\section{Item Selection: Exploratory Factor Analysis}

We first conducted exploratory factor analyses (EFA) for item selection with sample 1 $(N=421)$. The Kaiser-Meyer-Olkin measure of sampling adequacy for the initial EFA was .86, and Bartlett's test of sphericity $\left[\chi^{2}(105)=2277.34, p<.001\right]$ indicated that the correlation matrix was appropriate for factor analysis. To determine the number of factors, we conducted a parallel analysis and scree plot. First, parallel analysis (Brown 2006; Kahn 2006) was used with 100 random correlations matrices and 1000 seeds to determine the number of factors to extract. Parallel analysis results suggested two factors, which was the number of factors where the eigenvalues of the Sample 1 dataset (2.81) remained higher than the respective 95-percentile eigenvalue from a randomly generated dataset (1.31). Scree plot suggested two or three factors. We thus conducted principal axis factor analyses on the 15 items with two- and three-factor solutions using oblique (Promax) rotations. The 
two-factor solution was readily interpretable, whereas the three-factor solution had excessive cross-loadings and only two clean items (i.e., loading over .40 on one factor and no cross-loading over .20) on the third factor. The two factors were consistent with the two categories-Standards and Discrepancy, in which the items were developed. All items had (a) a factor loading greater than .40 (Netemeyer et al. 2003), (b) cross-loading less than .20, (c) consistency between factor and item category. With the goal of developing a brief measure, we only retained five items representing each factor (Tabachnick and Fidell 2007). The five items for each factor were selected based on (a) higher factor loadings and (b) minimal content overlap. Another EFA using principal axis factor was conducted with the 10 selected items. The two-factor 10 -item solution accounted for $55.46 \%$ of the total variance explained before rotation. After the oblique rotation, all factor loadings exceeded .40 on the respective factor, and no item had a cross-loading over .20 on the other factor. Each of the items representing the two factors and their factor loadings, communality estimate, mean, and standard deviation are presented in Table 1.

\section{Cross-Validation: Confirmatory Factor Analysis}

Confirmatory factor analysis (CFA) was conducted with sample $2(N=420)$ using Mplus 7 to cross-validate the measurement qualities of the PPGS based on the principal axis factor analysis results. We first examined a two-factor oblique model using MLR as the estimator and Geomin as the rotation method. The CFA model constrained the 10 PPGS items to load onto their corresponding factors based on the EFA results. The two factors were permitted to correlate with one another. CFA results supported a two-factor oblique model $[\mathrm{CFI}=.940, \mathrm{SRMR}=.039$, RMSEA $=.066]$. The ranges of standardized factor loadings for the factors were: .58-.75 for God's Standards, .68-.80 for God's Discrepancy. We also examined three competing models: a two-factor orthogonal model, a bifactor model (i.e., each item loads onto both a general God Perfectionism factor and one of the two orthogonal factor), and a one-factor model. The fit indices for all four models are presented in Table 2. Based on the general guidelines, the CFI, SRMR, and RMSEA, all indicated an adequate data to model fit for both the two-factor oblique and the bifactor model, a marginal fit for the two-factor orthogonal model, and an unacceptable fit for the one-factor model. To compare between the two-factor oblique and the bifactor model, we examined the Akaike information criteria (AIC). A slightly smaller AIC indicated that the bifactor model (AIC $=13,353.33$ ) was better than the two-factor oblique model $(\mathrm{AIC}=13,379.29)$; moreover, the bifactor model also had better fit indices [CFI $=.969$, $\mathrm{SRMR}=.031, \mathrm{RMSEA}=.056]$. In sum, these results indicated that the two factors share commonalities due to the good fit for the bifactor model, but are distinct factors due to the unacceptable fit for the single factor model.

\section{Measurement Invariance Across Genders}

We conducted a multiple-group CFA to examine measurement invariance of the two-factor oblique model between men and women using a forward (sequential constraint imposition) approach (see Table 3). The first step involved establishing configural invariance by examining models for each gender group separately. Results indicated adequate fit for both groups [men: $\operatorname{MLR} \chi^{2}(34, n=212)=56.57, p=.009, \mathrm{CFI}=.942$, RMSEA $=.056$, SRMR $=.044 ; \quad$ women: $\quad \operatorname{MLR} \chi^{2}(34, \quad n=208)=71.06, \quad p<.001, \quad$ CFI $=.944$, $\mathrm{RMSEA}=.072, \mathrm{SRMR}=.042]$. Measurement invariance was examined next, which involved establishing a baseline model (Model 0: Unconstrained Model), and then testing 
Table 1 Exploratory factor analysis-items, factor loadings, means and standard deviations for the PPGS

Factors

$\overline{1} 2 \quad h^{2} \quad$ Mean $\mathrm{SD}$

Perceived discrepancy from God

9. God is hardly ever satisfied with my performance

$\begin{array}{lllll}\mathbf{8 0} & -.15 & .65 & 1.90 & 1.06\end{array}$

2. My best just never seems to be good enough for God

$\begin{array}{lllll}.75 & .04 & .56 & 2.20 & 1.32\end{array}$

7. I am seldom able to meet God's high standards of performance

$\begin{array}{lllll}.72 & .05 & .52 & 3.11 & 1.56\end{array}$

4. I rarely live up to God's high standards

$\begin{array}{lllll}.71 & .04 & .51 & 3.11 & 1.53\end{array}$

10. God is often disappointed because He knows I could have done

$\begin{array}{lllll}.58 & .05 & .35 & 2.94 & 1.61\end{array}$ better

\section{Perceived standards from God}

3. God has high expectations for me

$\begin{array}{lllll}-.10 & .70 & .49 & 6.30 & .98\end{array}$

5 . God sets very high standards for me

$\begin{array}{lllll}.09 & \mathbf{6 5} & .43 & 5.74 & 1.48\end{array}$

8. God expects me to have a strong need to strive for excellence

$\begin{array}{lllll}.09 & .61 & .39 & 5.60 & 1.38\end{array}$

1. God has high standards for my performance at work or at school

$\begin{array}{lllll}.05 & .57 & .33 & 5.60 & 1.35\end{array}$

6. God expects the best from me

$\begin{array}{lllll}-.09 & \mathbf{4 9} & .25 & 6.28 & 1.01\end{array}$

Final 10 PPGS items. Highest factor loadings are in bold. $N=421$ participants (Sample 1). Factor $1=$ Perceived Discrepancy from God; Factor $2=$ Perceived Standards from God. $h^{2}=$ item communalities at extraction. Cronbach alphas were .73 for Perceived Standards from God and .82 for Perceived Discrepancy from God. Each item was rated on a 7-point Likert Scale $(1=$ strongly disagree, $7=$ strongly agree). The instructions to participants were: The following items are designed to measure how you think God perceives you. The term "God" refers to the higher power(s) of your religious orientation. Use your first impression and indicate how much you agree with each item

Table 2 Goodness-of-fit indicators for the competing models of the 10-item PPGS

\begin{tabular}{lrlllll}
\hline Model & MLR $\chi^{2}$ & $d f$ & CFI & RMSEA [CI] & SRMR & AIC \\
\hline Two-factor oblique & 97.05 & 34 & .940 & $.066[.051-082]$ & .039 & $13,379.29$ \\
Two-factor orthogonal & 110.71 & 35 & .928 & $.072[.057-087]$ & .073 & $13,390.51$ \\
Bifactor & 57.76 & 25 & .969 & $.056[.037-075]$ & .031 & $13,353.33$ \\
One factor & 458.19 & 35 & .599 & $.170[.156-184]$ & .157 & $13,859.84$ \\
\hline
\end{tabular}

$N=420$ (Sample 2)

$P P G S$ Perceived Perfectionism from God Scale, $C F I$ comparative fit index, $R M S E A$ root-mean-square error of approximation, $C I$ confidence interval for RMSEA, SRMR standardized root-mean-square residual, AIC Akaike information criteria

for equal factor loading across groups (Model 1: Invariant Factor Loadings Model), equal item intercepts across groups (Model 2: Invariant Factor Loadings and Intercepts Model), and equal item error variances/covariances across groups (Model 3: Invariant Factor Loadings, Intercepts, and Residual Variances Model). Nested models were compared using MLR scaled $\chi^{2}$ difference tests. Due to the sensitivity of $\chi^{2}$ to sample size, we also examined CFI and RMSEA differences between models, with cutoffs of .01 for CFI (Cheung and Rensvold 2002) and .015 for RMSEA (Chen 2007). In Model 0 (M0), no parameters were constrained to be equal across the two gender groups. Factor loadings 
Table 3 Testing for measurement invariance across gender groups

\begin{tabular}{lrllllllll}
\hline & MLR $\chi^{2}$ & $d f$ & M comp & MLR $\Delta \chi^{2}$ & $\Delta d f$ & $p$ & CFI & RMSEA & SRMR \\
\hline Male & 56.57 & 34 & & & & & .942 & .056 & .044 \\
Female & 71.06 & 34 & & & & & .944 & .072 & .042 \\
[M0] Unconstrained & 126.74 & 68 & & & & & .944 & .064 & .043 \\
[M1] Loadings & 142.79 & 76 & M1-M0 & 15.82 & 8 & 0.05 & .936 & .065 & .072 \\
[M2] Loadings, Intercepts & 155.69 & 84 & M2-M1 & 12.67 & 8 & 0.12 & .932 & .064 & .068 \\
[M3] Loadings, Intercepts, & 151.19 & 94 & M3-M2 & 8.51 & 10 & 0.58 & .945 & .054 & .074 \\
$\quad$ Residual Variances & & & & & & & & & \\
\hline
\end{tabular}

$N=420$ (208 women, 212 men)

$M L R$ robust maximum likelihood, $C F I$ comparative fit index, RMSEA root-mean-square error of approximation, $S R M R$ standardized root-mean-square residual $[M O]$. The baseline model (i.e., all parameters freely estimated). [MI] The Invariant Factor Loadings Model (i.e., constraining all factor loadings to be equal across the two groups). [M2] The Invariant Factor Loadings and Intercepts Model (i.e., constraining all factor loadings and intercepts to be equal across the two groups). [M3] The Invariant Factor Loadings, Intercepts and Residual Variances Model (i.e., constraining all factor loadings, intercepts and residual variances to be equal across the two groups)

were constrained to be equal across groups in Model 1 (M1). A significant MLR $\Delta \chi^{2}$ difference between M1 and M0 [MLR $\left.\Delta \chi^{2}(8)=15.82, p=.045\right]$ indicated a slight metric variance (i.e., variant factor loadings); however, the $p$ value was just below .05. Thus, we also considered the difference in CFI $(-.008)$ and RSMEA $(+.001)$, which both indicated that M1 did not have a significantly worse model fit than M0. Based on overall comparisons of indices, metric invariance was concluded. Next, both factor loadings and item intercepts were constrained to be equal between two gender groups in Model 2 (M2). The $\operatorname{MLR} \Delta \chi^{2}$ between M2 and M1 was nonsignificant [MLR $\Delta \chi^{2}(8)=12.67, p=.12$ ], indicating that the intercepts were invariant between the two gender groups. The difference between M2 and M1 in CFI (-.004) and RSMEA (-.001) also supported invariance in item intercepts. Model 3 (M3) added constraints for residual item variances/covariances to be equal between genders. The nonsignificant MLR $\Delta \chi^{2}$ difference between M3 and M2 $\left[\operatorname{MLR} \Delta \chi^{2}(10)=8.51, p=.58\right]$ indicated that item error variances/covariances were also invariant between genders, which was also supported by the nonsignificant CFI and RMSEA differences. In sum, multiple-group CFA results indicated that the RDS demonstrated overall measurement invariance between men and women in this LDS sample.

\section{Construct Validity}

To examine the construct validity of the PPGS, we conducted correlations between PPGS subscale scores with other study variables in Sample 2 (Table 4). Convergent-discriminant validity was assessed through the associations between PPGS and SAPS subscales. Convergent validity was supported by PPGS Standards and Discrepancy from God being positively correlated with one's personal SAPS Standards and Discrepancy, respectively. Discriminant validity was supported through the nonsignificant correlations between PPGS Standards and SAPS Discrepancy as well as PPGS Discrepancy and SAPS Standards. In addition, none of the PPGS and SAPS subscale scores correlated significantly with Social Desirability scores. The validity of the PPGS was supported by its associations with psychological well-being, in which Standards from God was positively correlated with 


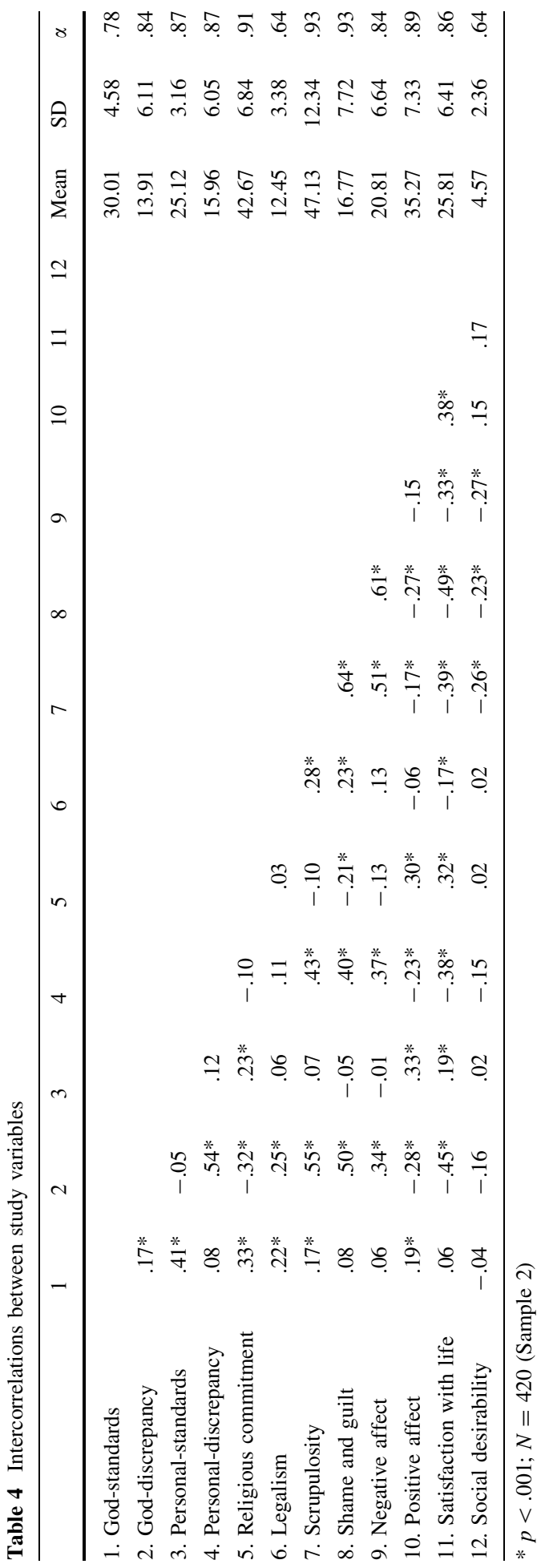


positive affect, whereas Discrepancy from God was positively correlated with Negative Affect, Shame, and Guilt. Moreover, being religiously committed was associated with higher Standards, but lower Discrepancy from God. Both Perceived Standards and Discrepancy from God were both positively associated with legalistic beliefs and scrupulosity. However, perceived Discrepancy from God was much more strongly associated with Scrupulosity compared to Standards from God.

\section{Incremental Validity}

We conducted hierarchical regressions to examine the incremental validity of the new PPGS subscale scores. In specific, we sought whether PPGS subscale scores significantly explained relevant constructs over and above personal perfectionism (i.e., Personal-Standards and Personal-Discrepancy subscales from SAPS). As for PPGS Standards subscale, Religious Commitment was included in the analyses as the dependent variable. The result showed that there was a significant incremental predictability of PPGS Standards scores over SAPS Standards scores, explaining an additional $7 \%$ of the variance.

We entered scrupulosity as the dependent variable to examine the incremental validity of PPGS Discrepancy. First, in step 1, we entered related study variables (e.g., Shame, Guilt). In step 2, the SAPS Discrepancy was entered (see Table 5). In step 3, PPGS Discrepancy was entered. The incremental variance of PPGS Discrepancy in predicting scrupulosity above and beyond Shame and Guilt and SAPS Discrepancy was 5\%. These

Table 5 Hierarchical regressions for incremental validity in predicting religious commitment and scrupulosity above and beyond related variables

\begin{tabular}{|c|c|c|c|c|c|c|}
\hline & $B$ & $S E$ & $\beta$ & $\Delta R^{2}$ & $\Delta F$ & $d f \mathrm{~s}$ \\
\hline \multicolumn{7}{|l|}{ Religious commitment } \\
\hline Step 1 & & & & $.05 * * *$ & 22.49 & 1,418 \\
\hline Personal-standards & .49 & .10 & $.23 * * *$ & & & \\
\hline Step 2 & & & & $.07 * * *$ & 31.64 & 1,417 \\
\hline Personal-standards & .23 & .11 & $.11^{*}$ & & & \\
\hline God-standards & .42 & .08 & $.28 * * *$ & & & \\
\hline \multicolumn{7}{|l|}{ Scrupulosity } \\
\hline Step 1 & & & & $.41 * * *$ & 143.38 & 1,417 \\
\hline Shame & 1.01 & .17 & $.31 * * *$ & & & \\
\hline Guilt & 1.02 & .14 & $.38^{* * *}$ & & & \\
\hline Step 2 & & & & $.04 * * *$ & 28.74 & 1,416 \\
\hline Shame & .73 & .17 & $.22 * * *$ & & & \\
\hline Guilt & 1.01 & .14 & $.38 * * *$ & & & \\
\hline Personal-discrepancy & .44 & .08 & $.22 * * *$ & & & \\
\hline Step 3 & & & & $.05 * * *$ & 37.11 & 1,415 \\
\hline Shame & .33 & .18 & .10 & & & \\
\hline Guilt & 1.03 & .13 & $.39 * * *$ & & & \\
\hline Personal-discrepancy & .23 & .09 & $.11^{* *}$ & & & \\
\hline God-discrepancy & .57 & .09 & $.28 * * *$ & & & \\
\hline
\end{tabular}

$* p<.05 ; * * p<.01 ; * * * p<.001$ 
results suggested that the two PPGS subscales are different constructs from the previously entered personal SAPS subscales.

\section{Reliability and Other Correlations}

The internal consistency reliability for the PPGS subscale scores was overall adequate with Cronbach alphas all above .70 in both Samples 1 and 2. According to DeVellis (2012), internal consistencies between .70 to .80 are viewed as respectable, and those between .80 to .90 are viewed as very good. The Perceived Standards from God had Cronbach alphas of .73 (Sample 1) and .78 (Sample 2), whereas the Perceived Discrepancy from God had Cronbach alphas of .82 (Sample 1) and .84 (Sample 2).

\section{Discussion}

The purpose of this study was to develop a reliable and valid measure-Perceived Perfectionism from God Scale (PPGS) — to specifically assess one's perceived perfectionism from God with a clear distinction between the adapted and maladaptive components. The psychometric properties of the PPGS, a 10 item, 2-dimensional scale, were evaluated with two samples of Latter-day Saints. The results indicated that the PPGS is a promising measure with strong psychometrics properties. The internal consistency reliability coefficients for the PPGS subscale scores were adequate. The PPGS factor structure was supported through exploratory and confirmatory factor analyses. A comparison of different confirmatory factor analysis models indicated that the two-factor oblique model and the bifactor model were both adequate fits with the data. In sum, the PPGS appears to be a promising measure of perfectionism with religious individuals.

A primary strength of the PPGS is how it distinguishes between the adaptive and maladaptive aspects of perfectionism, which can offer better insights into how perfectionism affects religious individuals. Christianity as well as other religions often emphasizes perfection, which have been said to have the potential of causing emotional distress on its believers (Ellis 1986). However, the study provided evidence on how perceived perfectionism from God has multiple dimensions and how they are differentially associated with various religious factors and mental health indicators. For example, religious commitment was positively correlated with perceived standards from God, but negatively correlated with perceived discrepancy from God. This corresponds to Ashby and Huffman's (1999) study, in which results showed that religious individuals were high on adaptive perfectionism but low on maladaptive perfectionism. It was suggested that religious individuals are more likely to choose perfectionistic ways that will contribute to form or maintain healthy self-esteem and self-efficacy. Therefore, this finding refutes Ellis' claim that the more religious a person is, the more detrimental their perfectionism will be in causing distress. Our results indicated that the more religiously committed individuals are, the more likely they are to have perceived high standards from God, and less likely to feel maladaptively perfectionistic. Therefore, being religiously committed is not detrimental to one's mental health, which was also indicated through its positive correlation with positive affect and life satisfaction. In addition, perceived standards from God were associated with more positive affect, unlike perceived discrepancy from God, which was associated with stronger negative affect, shame and guilt. 
However, our hypothesis that adaptive and maladaptive aspects of perceived perfectionism from God would be differentially associated with positive (i.e., religious commitment) and negative (i.e., scrupulosity) religiosity was only partially supported. Although perceived standards and discrepancy from God correlated with religious commitment in different directions, these two perceived perfectionism from God aspects were both positively correlated with scrupulosity. This may be due to the interrelationship between Standards and Discrepancy (Eum and Rice 2011). In sum, perceiving the need to strive for perfection in itself is not detrimental to religious believers. This finding of the positive influence of striving for perfection was also supported by previous research (Allen and Wang 2014; Allen et al. 2015). However, it is the consistent feeling that one is not good enough or approved by God that can be an emotional stressor for believers.

This study also extends the literature on perfectionism and religion toward looking at how believers perceive their God or higher power. In other words, it is not just focusing on one's personal perfectionism, but more so their religiously prescribed perfectionism. Through the study, perceived perfectionism from God has also been shown to be a different construct from personal perfectionism. This distinction was supported through the incremental validity of the two perceived perfectionism from God dimensions-standards and discrepancy - predicting additional variances of related variables over and above personal perfectionistic standards and discrepancy, respectively. Therefore, whether a believer perceives his or her God as perfectionistic is different from whether the believer is a perfectionist, despite there being some connection between the two constructs. Moreover, based on correlational results, how believers perceive God can have stronger implications than whether they are simply perfectionists, especially when focusing on religious related factors, such as religious commitment, legalism, and scrupulosity. This is additional evidence that perception of God is associated with mental health outcome. Results of this study add to the literature in which previous studies contended positive association between closeness with God and positive mental and physical outcome (e.g., Homan and Boyatzis 2010; Krause 2007). This study highlights the importance of taking into account one's image of their God or higher power to better understand religious individuals.

\section{Limitations}

Despite the contributions of the study, there are a number of limitations worth noting. First, the PPGS was developed utilizing two samples of Latter-day Saints in the USA, whom were mostly in their early adulthood. Therefore, generalizability of the findings outside of Mormonism and with other age groups is limited. A future direction is to further examine the psychometric properties of the PPGS with other age and ethnic groups as well as those who hold other religious orientations. Second, this study is cross sectional; therefore, causal effects cannot be inferred. Another future research direction is to utilize experimental designs or longitudinal methods to better assess the predictability of perceived perfectionism from God on mental health and other outcome variables. Third, the Cronbach alpha of the MCSDS-Short A (.64) was less than desirable, though not unacceptable, based on DeVellis's (2012) guidelines. Future studies may use alternative scales to measure social desirability. Fourth, results of this study established the correlational relationships between PPGS with general religious variables and subjective well-being. It will also be useful to further examine possible mediating and moderating effects to understand the mechanism of how perceptions of God are associated with one's well-being. Qualitative approaches can also be used to explore the nuances with individuals whom have been influenced by distorted perceptions of God. 


\section{Implications}

Results of this study yield several practical implications. First, researchers, mental health practitioners and religious counselors can use the PPGS as a tool to assess religious individuals' interpretation of their religious commitment and beliefs as well as how they perceive their God. Assessment results can also be used to help these individuals become more aware of their perception of God and how it relates and affects their daily well-being. Gaining awareness of their perceptions may facilitate a deeper desire for those in distress to explore possible reasons that they have come to perceive God and interpret their faith in a certain way.

Second, assessment results could also be used to focus on the perfectionistic beliefs that the individuals hold as well as messages received regarding their religion. Using a Christian example, it would be helpful to explore how the Bible verse "You therefore must be perfect, as your heavenly Father is perfect." (Matthew 5:48) is interpreted. The command to be perfect can be interpreted as a continuous striving or as needing to meet perfection at the current moment, which are two very different notions that parallel the adaptive and maladaptive aspects of perfectionism. The need to continuously strive and seeing perfection as a process of development and growth (MacKenna 2002) resonates with perceiving God as having high standards. However, feeling the need to meet perfection at the current moment (which is impossible) can amplify the feeling that one is not good enough in God's eyes, which is in line with the maladaptive perfectionistic aspect.

Third, the idea of what the perfect person in God's eyes is like can also be explored with religious individuals dealing with perfectionistic struggles. A discussion on this topic could help the individual gain a better understanding of what they are striving for and also provide an opportunity to compare their views with teachings from their religion. Any distorted perceptions that may have been influenced by individuals' family environment, life experiences, or certain messages can be explored and possibly replaced with concepts that are more in line with their religious theological doctrine.

In sum, the importance of looking at perfectionism among religious individuals cannot be neglected. However, more attention is to be focused on differentiating the adaptive and maladaptive aspects of perfectionism as well as whether the perfectionism originates from the individuals or their perceptions of God. It is not until these components are better understood in detail that one can better help religious believers untangle their struggles with perfectionism.

Funding The authors wish to acknowledge an internal research grant from the David O. McKay School of Education at Brigham Young University that supported this study.

\section{Compliance with Ethical Standards}

Conflict of interest All authors declare that they have no conflict of interest.

Ethical Approval All procedures performed in studies involving human participants were in accordance with the ethical standards of the institutional and/or national research committee and with the Declaration of Helsinki 1964 and its later amendments or comparable ethical standards.

Informed Consent Informed consent was obtained from all individual participants included in the study. 


\section{References}

Abramowitz, J. S., Huppert, J. D., Cohen, A. B., Tolin, D. F., \& Cahill, S. P. (2002). Religious obsessions and compulsions in a non-clinical sample: The penn inventory of scrupulosity (PIOS). Behaviour Research and Therapy, 40(7), 824-838.

Allen, G. E. K., \& Heppner, P. P. (2011). Religiosity, coping, and psychological well-being among LatterDay Saint Polynesians in the U.S. Asian American Journal of Psychology, 2, 13-24.

Allen, G. E. K., \& Wang, K. T. (2014). Examining religious commitment, perfectionism, scrupulosity, and well-being among LDS individuals. Psychology of Religion and Spirituality, 6, 257-264.

Allen, G. E. K., Wang, K. T., Stokes, H. (2015). Examining legalism, scrupulosity, family perfectionism, and psychological adjustment among LDS individuals. Mental Health, Religion \& Culture, 18, 246-258. doi:10.1080/13674676.2015.1021312.

Ashby, J. S., \& Huffman, J. (1999). Religious orientation and multidimensional perfectionism: Relationships and implications. Counseling and Values, 43(3), 178-188.

Bieling, P. J., Israeli, A. L., \& Antony, M. M. (2004). Is perfectionism good, bad, or both? Examining models of the perfectionism construct. Personality and Individual Differences, 36, 1373-1385.

Brown, T. A. (2006). Confirmatory factor analysis for applied research. New York: Guilford Press.

Chen, F. F. (2007). Sensitivity of goodness of fit indexes to lack of measurement invariance. Structural Equation Modeling, 14, 464-504. doi:10.1080/10705510701301834.

Cheung, G. W., \& Rensvold, R. B. (2002). Evaluating goodness-of-fit indexes for testing measurement invariance. Structural Equation Modeling, 9, 233-255. doi:10.1207/s15328007sem0902_5.

Craddock, A. E., Church, W., Harrison, F., \& Sands, A. (2010). Family of origin qualities as predictors of religious dysfunctional perfectionism. Journal of Psychology and Theology, 38, 205-214.

Crawford, J. R., \& Henry, J. D. (2004). The positive and negative affect schedule (PANAS): Construct validity, measurement properties and normative data in a large non-clinical sample. British Journal of Clinical Psychology, 43, 245-265.

Crosby, J. M., Bates, S. C., \& Twohig, M. P. (2011). Examination of the relationship between perfectionism and religiosity as mediated by psychological inflexibility. Current Psychology, 30, 117-129.

Crowne, D. P., \& Marlowe, D. (1960). A new scale of social desirability independent of psychopathology. Journal of Consulting Psychology, 24(4), 349-354.

DeVellis, R. F. (2012). Scale development: Theory and applications (Vol. 26). Thousand Oaks: Sage Publications.

Ellis, A. (1986). Do some religious beliefs help create emotional disturbance? Psychotherapy in Private Practice, 4, 101-106.

Eum, K., \& Rice, K. G. (2011). Test anxiety, perfectionism, goal orientation, and academic performance. Anxiety Stress and Coping, 24(2), 167-178.

Frost, R. O., Marten, P., Lahart, C., \& Rosenblate, R. (1990). The dimensions of perfectionism. Cognitive Therapy And Research, 14(5), 449-468.

Grzegorek, J. L., Slaney, R. B., Franze, S., \& Rice, K. G. (2004). Self-criticism, dependency, self-esteem, and grade point average satisfaction among clusters of perfectionists and nonperfectionists. Journal of Counseling Psychology, 51, 192-200.

Heise, R. G., \& Steitz, J. A. (1991). Religious perfectionism versus spiritual growth. Counseling and Values, 36, 11-18.

Hewitt, P. L., \& Flett, G. L. (1991). Perfectionism in the self and social contexts: Conceptualization, assessment, and association with psychopathology. Journal of Personality and Social Psychology, 60, $456-470$.

Homan, K. J., \& Boyatzis, C. J. (2010). Religiosity, sense of meaning, and health behavior in older adults. The International Journal for the Psychology of Religion, 20, 173-186.

Kahn, J. H. (2006). Factor analysis in counseling psychology research, training, and practice: Principles, advances, and applications. The Counseling Psychologist, 34, 684-718.

Krause, N. (2007). Stressors arising in highly valued roles and change in feeling close to God over time. The International Journal for the Psychology of Religion, 17, 17-36.

Loo, R., \& Thorpe, K. (2000). Confirmatory factor analyses of the full and short versions of the MarloweCrowne Social Desirability Scale. The Journal of Social Psychology, 140, 628-635.

MacKenna, C. (2002). Self images and god images. British Journal of Psychotherapy, 18, 325-338.

Marschall, D., Sanftner, J., \& Tangney, J. P. (1994). The state shame and guilt scale. Fairfax: George Mason University.

Michalak, L., Trocki, K., \& Bond, J. (2007). Religion and alcohol in the US National Alcohol Survey: How important is religion for abstention and drinking? Drug and Alcohol Dependence, 87, 268-280. 
Netemeyer, R. G., Bearden, W. O., \& Sharma, S. (Eds.). (2003). Scaling procedures: Issues and applications. London: Sage.

Patterson, R. E., Wang, K. T., \& Slaney, R. B. (2012). Multidimensional perfectionism, depression and relational health in women with eating disturbances. Eating Behaviors, 13, 226-232.

Pavot, W., \& Diener, E. (1993). Review of the satisfaction with life scale. Psychological Assessment, 5, $164-172$.

Rasmussen, K. R., Yamawaki, N., Moses, J., Powell, L., \& Bastian, B. (2013). The relationships between perfectionism, religious motivation, and mental health utilisation among Latter-Day Saint students. Mental Health, Religion \& Culture, 16, 612-616.

Reynolds, W. M. (1982). Development of reliable and valid short forms of the Marlowe-Crowne Social Desirability Scale. Journal of Clinical Psychology, 38, 119-125. doi:10.1002/1097-4679(198201)38: 1119::AID-JCLP22703801183.0.CO;2-I.

Rice, K. G., Richardson, C. E., \& Tueller, S. (2014). The short form of the revised almost perfect scale. Journal of Personality Assessment, 96, 368-379.

Rice, K. G., \& Slaney, R. B. (2002). Clusters of perfectionists: Two studies of emotional adjustment and academic achievement. Measurement and Evaluation in Counseling and Development, 35, 35-48.

Shea, A. J., Slaney, R. B., \& Rice, K. G. (2006). Perfectionism in intimate relationships: The dyadic almost perfect scale. Measurement and Evaluation in Counseling and Development, 39, 107-125.

Slaney, R. B., Pincus, A. L., Uliaszek, A. A., \& Wang, K. T. (2006). Conceptions of perfectionism and interpersonal problems: Evaluating groups using the structural summary method for circumplex data. Assessment, 13, 138-153.

Slaney, R. B., Rice, K. G., Mobley, M., Trippi, J., \& Ashby, J. S. (2001). The revised almost perfect scale. Measurement and Evaluation in Counseling and Development, 34, 130-145.

Stoeber, J., Harris, R. A., \& Moon, P. S. (2007). Perfectionism and the experience of pride, shame, and guilt: Comparing healthy perfectionists, unhealthy perfectionists, and non-perfectionists. Personality and Individual Differences, 43, 131-141.

Stoeber, J., \& Otto, K. (2006). Positive conceptions of perfectionism: Approaches, evidence, challenges. Personality and Social Psychology Review, 10, 295-319.

Tabachnick, B. G., \& Fidell, L. S. (2007). Using multivariate statistics (5th ed.). Needham Heights: Allyn \& Bacon.

Wang, K. T. (2010). The family almost perfect scale: Development, psychometric properties, and comparing Asian and European Americans. Asian American Journal of Psychology, 1, 186-199.

Wang, K. T., Slaney, R. B., \& Rice, K. G. (2007). Perfectionism in Chinese university students from Taiwan: A study of psychological well-being and achievement motivation. Personality and Individual Differences, 42, 1279-1290.

Warner, J. (2009). Temperance, alcohol, and the American evangelical: A reassessment. Addiction, 104, 1075-1084.

Watson, P. J., Chen, Z., \& Sisemore, T. A. (2011). Grace and Christian psychology-Part 2: Psychometric refinements and relationships with self-compassion, depression, beliefs about sin, and religious orientation. Edification: The Transdisciplinary Journal of Christian Psychology, 4, 64-72.

Watson, D., Clark, L. A., \& Tellegen, A. (1988). Development and validation of brief measures of positive and negative affect: The PANAS scales. Journal of Personality and Social Psychology, 54, 1063-1070.

Worthington, E. J., Wade, N. G., Hight, T. L., Ripley, J. S., McCullough, M. E., Berry, J. W., et al. (2003). The Religious Commitment Inventory-10: Development, refinement, and validation of a brief scale for research and counseling. Journal of Counseling Psychology, 50, 84-96. 